\title{
Pending Studies at Hospital Discharge: A Pre-post Analysis of an Electronic Medical Record Tool to Improve Communication at Hospital Discharge
}

\author{
Molly A. Kantor, MD, Kambria H. Evans, MEd, and Lisa Shieh, MD, PhD
}

Stanford University School of Medicine, Stanford, CA, USA.

BACKGROUND: Achieving safe transitions of care at hospital discharge requires accurate and timely communication. Both the presence of and follow-up plan for diagnostic studies that are pending at hospital discharge are expected to be accurately conveyed during these transitions, but this remains a challenge.

OBJECTIVE: To determine the prevalence, characteristics, and communication of studies pending at hospital discharge before and after the implementation of an electronic medical record (EMR) tool that automatically generates a list of pending studies.

DESIGN: Pre-post analysis.

PATIENTS: 260 consecutive patients discharged from inpatient general medicine services from July to August 2013.

INTERVENTION: Development of an EMR-based tool that automatically generates a list of studies pending at discharge.

MAIN MEASURES: The main outcomes were prevalence and characteristics of pending studies and communication of studies pending at hospital discharge. We also surveyed internal medicine house staff on their attitudes about communication of pending studies.

KEY RESULTS: Pre-intervention, $70 \%$ of patients had at least one pending study at discharge, but only $18 \%$ of these were communicated in the discharge summary. Most studies were microbiology cultures (68\%), laboratory studies (16\%), or microbiology serologies (10\%). The majority of study results were ultimately normal $(83 \%)$, but $9 \%$ were newly abnormal. Postintervention, communication of studies pending increased to $43 \%(\mathrm{p}<0.001)$.

CONCLUSIONS: Most patients are discharged from the hospital with pending studies, but in usual practice, the presence of these studies has rarely been communicated to outpatient providers in the discharge summary. Communication significantly increased with the implementation of an EMR-based tool that automatically generated a list of pending studies from the EMR and allowed users to import this list into the discharge summary. This is the first study to our knowledge to introduce an automated EMR-based tool to communicate pending studies.

Received April 9, 2014

Revised August 18, 2014

Accepted September 25, 2014

Published online November 22, 2014
KEY WORDS: Applied informatics; Care transitions; Electronic health records; Continuity of care; Health information technology; Hospital medicine; Medical informatics; Patient safety; Quality improvement; Communication.

$\mathrm{J}$ Gen Intern Med 30(3):312-8

DOI: $10.1007 / \mathrm{s} 11606-014-3064-\mathrm{x}$

(c) Society of General Internal Medicine 2014

\section{INTRODUCTION}

Achieving safe transitions of care at discharge from the hospital to the ambulatory care setting requires accurate and timely communication. Communication failures during these care transitions can lead to medication errors, duplication of diagnostic testing, delays in diagnosis and treatment, and increased rates of rehospitalization. ${ }^{1-10}$ The discharge summary is the primary method of communication at hospital discharge. $^{5,11}$ There is widespread agreement that the discharge summary should communicate both the presence of and follow-up plan for diagnostic studies that are pending at hospital discharge. ${ }^{5,12-15}$ However, only $12-16 \%$ of pending studies are communicated in discharge summaries. ${ }^{16-18}$ This is problematic, as previous authors have shown that $41 \%$ of medical patients are discharged with at least one pending study, and $43 \%$ of the results of these studies were eventually abnormal. $^{19}$

Despite the need for quality improvement in this area, many of the efforts aimed at improving safety in transitions of care have focused on communication and care coordination without specifically addressing pending studies. ${ }^{3,20}$ Unfortunately, these communication challenges are likely to become more difficult for several reasons: greater incentives for shorter lengths of hospital stay, inpatient care increasingly delivered by hospitalists rather than primary care physicians, and more hand-offs in the inpatient setting due to restrictions on house staff work hours. ${ }^{14,15,21-23}$ To our knowledge, only one previous study has attempted quality improvement in this area, by prompting the discharging provider to manually list pending studies using a discharge order set. ${ }^{18}$ However, this method is prone to error, as discharging inpatient physicians are often unaware of studies that have been ordered or for which results are still pending. ${ }^{19}$ 
We responded to this challenge by utilizing the electronic medical record (EMR) to create a tool that automatically generated a list of studies pending at discharge. We conducted a quality improvement study at our academic teaching hospital to better understand (1) the frequency at which patients were discharged from the inpatient general medicine service with pending studies as well as the characteristics of these studies, and (2) the quality of communication of pending studies in the discharge summary before and after the implementation of this EMR-based tool.

\section{METHODS}

\section{Design Overview}

We conducted a prospective quality-improvement study on the general medicine inpatient wards at an academic tertiary care hospital. We conducted a pre-post analysis of communication at discharge regarding pending studies before and after the introduction of an EMR-based tool that automatically generated a list of pending studies and which could be imported into the discharge summary.

\section{Setting and Participants}

Our study was conducted at a 613-bed academic tertiary care hospital located in Stanford, California, that both serves the local community and is a regional referral center for patients with complex medical needs. ${ }^{24}$ At our institution, the general medicine inpatient services comprise an attending physician, one junior or senior resident, two interns, and one or two medical students, one of whom may be a sub-intern. The attending physician is typically a full-time hospitalist, although a minority are sub-specialists who attend on the general medicine wards for several weeks per year. The discharge summary is generally written by the discharging intern or resident and is finalized and signed by the attending physician. All house staff use computer-based charting rather than dictation to complete discharge summaries. A discharge summary note template is available that automatically imports patient information from the EMR and also allows modification and free-text entry. Our institution uses the EpicCare electronic medical record system (Epic Systems Corporation, Verona, WI) as our EMR system, which is a comprehensive medical record that incorporates both inpatient and outpatient notes, computerized physician order entry, and laboratory and radiology studies. This study was exempted from review by the Stanford IRB.

\section{Data Collection}

Data were gathered by EMR chart review from all consecutive patients discharged from the general medicine wards during a period of one month from July to August 2013. The intervention was introduced on August 9, 2013. Patients were excluded from the study if they died during the hospitalization, were discharged on hospice care, were transferred to another primary service in the hospital (such as psychiatry or surgery) or to another acute care hospital, or left against medical advice. Patients who were readmitted during the study period were included separately for each hospitalization. Patients discharged to subacute care facilities were included.

\section{Intervention}

Through our EMR, we created a programmed tool that automatically retrieved a list of pending laboratory, microbiology, and pathology studies. Studies were considered pending if the status of the study was not final, including studies that had a preliminary result or were still in process. We implemented our intervention by making the EMR tool available to all physicians to be used at their discretion, including in the discharge summary. Our house staff were informed and educated about the EMR tool through a combination of verbal announcements, demonstrations at teaching conferences, small group tutorials, and e-mail notifications.

\section{Frequency of Patients Discharged with Pending Studies, Study Categories, and Study Results}

To determine the frequency of patients discharged with pending studies, all charts were reviewed within 24 hours of discharge for the presence of pending studies, which was assessed by automatic data-gathering from the EMR and verified by manual review. Studies were considered pending if the status of the study was not final, including studies that had a preliminary result or were still in process. Studies were categorized as microbiology cultures, microbiology serologies, laboratory studies, pathology studies, or radiology studies.

To determine study results, charts were reviewed until all results of pending studies were finalized. The final result of each pending study was categorized as normal, newly abnormal, or abnormal as previously known. The category of newly abnormal was chosen to study as these results would be expected to involve a change in management. The institution normal range was used to determine whether a result was normal or abnormal. A physician reviewer (MK) used clinical judgment to determine whether an abnormal result was newly abnormal or previously known to be abnormal by comparison with both previous results since hospital admission and the discharge summary narrative. Any ambiguities were resolved upon discussion with the discharging attending physician. To preserve patient safety, all newly abnormal results were directly communicated to the discharging inpatient physicians. 


\section{Communication of Pending Studies}

To determine communication of pending studies, the aforementioned process was undertaken to first determine the presence of pending studies. Charts were then reviewed regularly until the discharge summary was completed and finalized by the attending physician. A physician reviewer (MK) reviewed the discharge summary for documentation of each pending study, including in list format or in narrative text. A study was considered to be communicated as pending if the discharge summary documented that the study was pending, not finalized, outstanding, in process, or needed follow-up. Clinical judgment was used to classify any ambiguities.

\section{Survey of Internal Medicine House Staff}

We surveyed internal medicine house staff on their awareness of, communication of, and attitudes towards responsibility of studies pending at hospital discharge. Questions regarding opinions on the discharge process were scored on a 100 point Likert scale, with 0 indicating "never" and 100 indicating "always" for questions regarding frequency, and with 0 indicating "low" and 100 indicating "high" for questions regarding awareness. The survey was distributed through a house staff Listserv, with an e-mail reminder sent one week after the initial e-mail. Data were collected using Qualtrics software (Qualtrics, Provo, UT).

\section{Statistical Analysis}

Categorical variables and proportions were analyzed using the $\chi^{2}$ test.

\section{RESULTS}

\section{Frequency of Patients Discharged with Pending Studies, Study Categories, Study Results}

There were no statistical differences between pre- and postintervention data for frequency of patients discharged with pending studies $(p=0.34)$ or study results $(p=0.29)$; study categories were significantly different $(p=0.04)$. Table 1 illustrates pre- and post-intervention frequency, category, and results of pending studies. Pre-intervention $(n=108), 70 \%$ of patients discharged from the general medicine wards had one or more studies pending at discharge (mean: 2.1, range: 0-13; Table 1). Post-intervention ( $\mathrm{n}=152), 76 \%$ of patients were discharged with at least one pending study (mean: 2.3, range: 0-20; Table 1). Table 2 demonstrates examples of pending studies. Table 3 lists the most common pending laboratory and microbiology serology studies with their expected turnaround time and whether they are run in-house or sent out to reference laboratories; these 16 studies represent $42 \%$ of pending studies in these categories.

Pre-intervention, $9 \%$ of the final results of the pending studies were newly abnormal, with $83 \%$ normal and $8 \%$ abnormal but previously known (see Table 1). Postintervention, $13 \%$ of studies generated newly abnormal results, with $78 \%$ of results normal and $9 \%$ abnormal but previously known. There was no statistical difference in the study results comparing pre- and post-intervention ( $\mathrm{p}=0.29$, see Table 1). Table 2 demonstrates examples of newly abnormal results. Pathology studies and laboratory tests were more commonly newly abnormal (36-50\% and 22-26\%, respectively), while microbiology cultures and serologies were more likely to have normal results ( $89 \%$ and $75-91 \%$, respectively) (see Table 4).

\section{Communication of Pending Studies}

Pre-intervention, only $18 \%$ of pending studies were communicated in the discharge summary. On average, 2.5 studies per patient were not communicated. Only $7.6 \%$ of discharge summaries communicated all of the pending studies for an individual patient in the preintervention period.

After the implementation of our EMR tool, communication of pending studies increased from $18 \%$ to $43 \%$ (p $<0.001$ ). Post-intervention, discharge summaries communicating all pending studies for an individual patient increased from $7.6 \%$ to $26 \%(p=0.002)$. The EMR tool was used in $30 \%$ of the discharge summaries for patients with pending studies. A subgroup analysis was performed comparing communication of pending studies between discharge summaries that used the EMR tool and those that did not. Of discharge summaries that used the EMR tool, $74 \%$ communicated all studies pending at discharge, compared to $6 \%$ of discharge summaries that did not use the EMR tool $(\mathrm{p}<0.001)$.

\section{Survey of House Staff}

Seventy-nine of 111 house staff and sub-interns (71\% response rate) completed our survey. On average, they rated their frequency of communication of pending studies at 64.9 (scale: 0 indicating "never" and 100 indicating "always") and awareness of pending studies at 62.4 (scale: 0 indicating "low" and 100 indicating "high"). The majority of house staff ( $81 \%)$ considered the outpatient primary care physician responsible for following up on pending studies at discharge, but house staff also considered the discharging intern (43\%), resident (34\%), and outpatient specialist (39\%) responsible. Only $29 \%$ of house staff considered discharging attending physicians responsible for follow-up on pending studies. Almost half (48\%) of house staff physicians reported having a system 
Table 1. Comparison of frequency, category, and result of pending studies, pre- and post-intervention

\begin{tabular}{|c|c|c|c|}
\hline & Pre-intervention & Post-intervention & p value \\
\hline Frequency of pending studies & & & $\mathrm{p}=0.34$ \\
\hline Number of patients & 108 & 152 & \\
\hline Patients discharged with at least one pending study & $76(70 \%)$ & $115(76 \%)$ & \\
\hline Total number of pending studies (mean/patient) & 227 (2.1/patient) & $353(2.3 /$ patient $)$ & \\
\hline Study category & & & $\mathrm{p}=0.04$ \\
\hline Microbiology cultures & $155(68 \%)$ & $207(59 \%)$ & \\
\hline Microbiology serologies & $24(11 \%)$ & $34(10 \%)$ & \\
\hline Laboratory studies & $36(16 \%)$ & $72(20 \%)$ & \\
\hline Radiology studies & $6(3 \%)$ & $26(7 \%)$ & \\
\hline Pathology studies & $6(3 \%)$ & $14(4 \%)$ & \\
\hline Study result $(\%)$ & & & $\mathrm{p}=0.29$ \\
\hline Normal & $185(83 \%)$ & $274(78 \%)$ & \\
\hline Abnormal, previously known & $18(8 \%)$ & $31(9 \%)$ & \\
\hline Newly abnormal & $21(9 \%)$ & $47(13 \%)$ & \\
\hline
\end{tabular}

for follow-up of pending studies, and many commented that this consisted of a handwritten list.

\section{DISCUSSION}

We found that a surprisingly high percentage (70\%) of our general medicine patients were discharged from the hospital with at least one pending study, which contrasts with prior studies showing this to be $41 \% .{ }^{19}$ While it is possible that our institution is an outlier, we suspect that the discrepancy can be explained by systems changes. The previous study was conducted in 2004; in the interim decade, length of hospital stay has shortened and house staff work hours have become more restricted, leading to an increased number of hand- offs. ${ }^{14,15,19,21-23,25}$ While the average length of stay for hospitalized medical patients has shortened to less than four days, we found that many pending studies were cultures without finalized results or tests with turn-around time of five days or more (see Table 3) ${ }^{25}$ To our knowledge, we are the first to reexamine the prevalence of pending studies in this new environment. This observed marked increase in the number of patients discharged from the hospital with pending studies highlights the importance of accurate communication of these studies and their followup plans.

We also showed that availability of an EMR tool that automatically imported a list of pending studies significantly increased the communication of studies that were pending at hospital discharge. Prior to our intervention, only $18 \%$ of

Table 2. Representative examples of pending studies and newly abnormal results

\begin{tabular}{|c|c|c|}
\hline Category & Example of pending studies & Example of newly abnormal results \\
\hline Laboratory studies & $\begin{array}{l}\text { - Methylmalonic acid, serum } \\
\text { - Anti-nuclear antibody } \\
\text { - Testosterone, total } \\
\text { - Antiphospholipid antibody panel } \\
\text { - Niacin } \\
\text { - Celiac disease screen }\end{array}$ & $\begin{array}{l}\text { - } 25 \text {-hydroxy vitamin D level of } 9 \mathrm{ng} / \mathrm{mL} \\
\text { - p-ANCA positive } \\
\text { - Thiamine level of } 2 \mathrm{nmol} / \mathrm{L} \\
\text { - Proteinase } 3 \text { antibody positive }\end{array}$ \\
\hline Microbiology cultures & $\begin{array}{l}\text { - Blood culture } \\
\text { - AFB culture, respiratory } \\
\text { - CSF culture } \\
\text { - Fungal culture } \\
\text { - Stool ova and parasites }\end{array}$ & $\begin{array}{l}\text { - Wound culture growing methicillin-resistant Staphylococcus aureus } \\
\text { - Blood culture growing Salmonella typhii } \\
\text { - Urine culture growing vancomycin-resistant Enterococcus }\end{array}$ \\
\hline Microbiology serologies & $\begin{array}{l}\text { - Histoplasma antigen, urine } \\
\text { - HIV-1 RNA quantitative PCR } \\
\text { - Cocci complement fixation } \\
\text { - Syphilis treponemal screen } \\
\text { - QuantiFERON }\end{array}$ & $\begin{array}{l}\text { - Hepatitis C viral RNA of } 1,770,000 \mathrm{IU} / \mathrm{mL} \\
\text { - Helicobacter pylori antibody-positive } \\
\text { - Detected West Nile IgM antibody in CSF } \\
\text { - Dengue fever antibody positive }\end{array}$ \\
\hline Pathology studies & $\begin{array}{l}\text { - Breast biopsy } \\
\text { - Colon biopsy } \\
\text { - Stomach biopsy } \\
\text { - Peritoneal fluid cytology } \\
\text { - Pancreatic cytology }\end{array}$ & $\begin{array}{l}\text { - Colon biopsy showing invasive adenocarcinoma } \\
\text { - Atypical pancreatic cells on fine-needle aspiration } \\
\text { - Colon biopsy showing active colitis with crypt abscesses }\end{array}$ \\
\hline Radiology studies & $\begin{array}{l}\text { - CT chest } \\
\text { - MRI knee } \\
\text { - GS renal artery } \\
\text { - Chest X-ray }\end{array}$ & $\begin{array}{l}\text { - Delayed gastric emptying on gastric emptying study } \\
\text { - CT chest revealing pulmonary nodules } \\
\text { - X-ray esophagram showing esophageal dysmotility }\end{array}$ \\
\hline
\end{tabular}


Table 3. Turn-around time and send-out status of common pending laboratory and microbiology serology studies

\begin{tabular}{|c|c|c|c|c|c|}
\hline Study name & Category & $\begin{array}{l}\text { Turnaround } \\
\text { Time }^{33}\end{array}$ & $\begin{array}{l}\text { In-house or } \\
\text { Send-out }^{33}\end{array}$ & Days run ${ }^{33}$ & $\begin{array}{l}\text { Batched } \\
\text { status }^{33}\end{array}$ \\
\hline ANCA & Laboratory study & 6 days & In-house & Monday-Saturday & Not batched \\
\hline Anti-nuclear antibody & Laboratory study & 5 days & In-house & Monday-Friday & Not batched \\
\hline Cocci complement fixation & $\begin{array}{l}\text { Microbiology } \\
\text { serology }\end{array}$ & $7-14$ days & Send-out & NA & NA \\
\hline Cocci immunodiffusion & $\begin{array}{l}\text { Microbiology } \\
\text { serology }\end{array}$ & 7-14 days & Send-out & NA & NA \\
\hline Dengue fever antibody & $\begin{array}{l}\text { Microbiology } \\
\text { serology }\end{array}$ & 5-7 days & Send-out & NA & NA \\
\hline Elastase, stool & Laboratory study & 9 days & Send-out & NA & NA \\
\hline Factor V Leiden & Laboratory study & $7-14$ days & In-house & Weekly & Batched \\
\hline Helicobacter pylori antibody & $\begin{array}{l}\text { Microbiology } \\
\text { serology }\end{array}$ & 5-7 days & In-house & Wednesday & Batched \\
\hline Helicobacter pylori antigen & $\begin{array}{l}\text { Microbiology } \\
\text { serology }\end{array}$ & 5-7 days & In-house & Thursday & Batched \\
\hline Niacin & Laboratory study & 3-9 days & Send-out & NA & NA \\
\hline $\begin{array}{l}\text { QuantiFERON test for latent } \\
\text { tuberculosis }\end{array}$ & $\begin{array}{l}\text { Microbiology } \\
\text { serology }\end{array}$ & 3-6 days & In-house & Tuesday-Sunday & Not batched \\
\hline Syphilis treponemal screen & $\begin{array}{l}\text { Microbiology } \\
\text { serology }\end{array}$ & $1-3$ days & In-house & Monday, Wednesday, Friday & Batched \\
\hline Thiamine & Laboratory study & 4 days & In-house & Monday-Friday & Not batched \\
\hline $\begin{array}{l}\text { Urine protein immunofixation } \\
\text { electrophoresis }\end{array}$ & Laboratory study & 7 days & In-house & $\begin{array}{l}\text { Monday, Tuesday, } \\
\text { Wednesday, Friday }\end{array}$ & Batched \\
\hline 25-hydroxy-vitamin D & Laboratory study & 7 days & In-house & Monday-Friday & Not batched \\
\hline
\end{tabular}

pending studies were communicated in the discharge summary, similar to previous studies. ${ }^{17,18}$ With the introduction of our EMR-based tool, communication increased from $18 \%$ to $43 \%$.

Despite the availability of this tool, however, fewer than half of pending studies were communicated in discharge summaries. We hypothesize that one of the main barriers to communication was a lack of standardized practices of work in the discharge process. ${ }^{8,11}$ Despite an enthusiastic response to the availability of the EMR tool, only $30 \%$ of discharge summaries actually utilized it. Our EMR tool required manual importation by users into the discharge summary note, and a busy physician or one without a standard practice of writing discharge summaries may forget to include the EMR tool.

In response, we have modified the discharge summary template so that it now contains this tool. We believe that pre-populating the discharge summary with a list of pending studies will both enhance communication to outpatient providers and prompt the discharging physician to contextualize each pending study in the discharge summary narrative. In addition, our EMR tool did not automatically retrieve pending radiology studies, and we have subsequently programmed a second EMR tool that can accomplish this. We also plan to include turn-around time and send-out status for all studies at the time of ordering, which may prompt providers to order fewer studies with long turn-around times. Finally, we have created a standard discharge process that includes beginning discharge summary notes at the time that the discharge order is signed, thus pre-populating the discharge summary template in real time to include an accurate list of pending studies as well as discharge medications and appointments.

To our knowledge, the only other study that attempted to improve communication of pending studies relied on prompting the discharging physician to manually list pending studies via a discharge order set; following this intervention, only $22 \%$ of studies were communicated. ${ }^{18}$ Our EMR-based tool has important advantages because it automatically generates a list of pending studies from the EMR rather than relying on human memory. This is especially important, as our survey found that house staff vastly overestimate their communication of pending studies, and previous studies have shown that discharging physicians are often unaware of which studies have been ordered and which results are still pending. ${ }^{19}$

Table 4. Result of pending study by category

\begin{tabular}{|c|c|c|c|c|c|c|}
\hline & \multicolumn{2}{|l|}{ Newly abnormal } & \multicolumn{2}{|c|}{ Abnormal, previously known } & \multicolumn{2}{|l|}{ Normal } \\
\hline & Pre-intervention & Post-intervention & Pre-intervention & Post-intervention & Pre-intervention & Post-intervention \\
\hline Laboratory test & $8(22 \%)$ & $19(26 \%)$ & $0(0 \%)$ & $2(3 \%)$ & $28(78 \%)$ & $51(71 \%)$ \\
\hline Microbiology culture & $5(3 \%)$ & $13(6 \%)$ & $12(8 \%)$ & $10(5 \%)$ & $138(89 \%)$ & $184(89 \%)$ \\
\hline Microbiology serology & $3(13 \%)$ & $3(9 \%)$ & $3(13 \%)$ & $0(0 \%)$ & $18(75 \%)$ & $31(91 \%)$ \\
\hline Pathology & $3(50 \%)$ & $5(36 \%)$ & $1(17 \%)$ & $4(29 \%)$ & $2(33 \%)$ & $5(36 \%)$ \\
\hline Radiology & $2(33 \%)$ & $7(27 \%)$ & $1(33 \%)$ & $15(58 \%)$ & $2(33 \%)$ & $4(15 \%)$ \\
\hline Overall & $21(9 \%)$ & $47(13 \%)$ & $18(8 \%)$ & $31(9 \%)$ & $188(83 \%)$ & $275(78 \%)$ \\
\hline
\end{tabular}


Given the frequency at which patients are discharged with pending studies, designating responsibility for follow-up is critical. Our survey showed that house staff consider multiple agents responsible for following up pending studies. The legal responsibility for follow-up of studies and communication of results to the patient and/or outpatient providers falls on the inpatient attending physician. ${ }^{26}$ However, in practice, it is essential for both the discharging and outpatient physicians to be aware of the results of pending studies. This is particularly important for results that are newly abnormal or require a change in management, which were $9-13 \%$ of those included in our study.

Achieving further gains in patient safety in this area will require improved management systems to facilitate appropriate follow-up of pending results. Our survey showed that many house staff do not have a systematic approach for result follow-up. While many institutions have systems that notify physicians of "critical" values, including microbiology cultures, these may fail to capture other results that may warrant action in certain clinical situations but not in others. This is especially concerning, as our study showed that microbiology results were very likely to have normal results, compared to pathology, in which half of the results were newly abnormal. Previous studies, primarily investigating follow-up of studies in the outpatient setting, have shown that without results management systems in place, abnormal results can be missed or overlooked, leading to delays in care. ${ }^{27-30}$ Few institutions have implemented standardized systems to help physicians manage studies that are pending at discharge, and those that have established such systems have noted poor adoption or have raised concerns regarding "alert fatigue."31,32 Future studies are needed to develop reliable systems for follow-up of pending studies.

Our study has several limitations. First, data were gathered from only one academic institution, limiting generalizability. The sample size was small, and the data were gathered from a limited time period, which may have been an outlier. We did not randomize patients and cannot exclude the possibility that the pre- and post-intervention groups differed in characteristics such as severity of illness or length of stay. In addition, we used written discharge summaries as a proxy for communication, although it is possible that other means of communication, such as e-mail, telephone call, or in-person discussion, were used. Finally, our institution uses a sophisticated EMR that was capable of generating a list of pending studies at discharge, a process that may not be available to institutions with other EMR systems.

There are several future directions for ongoing quality improvement work in this area. Determination and designation of the provider(s) responsible for following up and acting on pending studies at discharge are critical to maintaining patient safety, and the creation of results management systems is necessary to support this work. This work can also inform inpatient ordering behavior, particularly for studies that are likely to be pending at discharge and thus unlikely to change inpatient management. Finally, while we hypothesize that communication of pending results improves patient safety and quality of care while reducing the waste and cost of duplicate testing, we would like to study patient-centered outcomes such as timeliness of diagnosis.

\section{CONCLUSIONS}

Most patients are discharged from the hospital with pending studies, but in usual practice, the presence of these studies is rarely communicated to outpatient providers in the discharge summary. We are the first to show that communication was significantly increased with the implementation of an EMR-based tool that automatically generated a list of pending studies from the EMR and allowed users to import this list into the discharge summary. EMR-based tools can enhance the transition of care between inpatient and outpatient setting by improving communication, but standardized practices of work incorporating such tools into routine practice and results management systems to facilitate result follow-up are necessary.

Acknowledgements: We acknowledge and thank Marta Cook, BSN, $R N$, and Andrew Shelton, MD, for their contribution to the design and programming of the EMR tool; Pooja Loftus, MS, for reviewing the statistical analysis; and Neil Shah, MD, for assistance with information on laboratory practices. We have no funding sources to disclose. This work was previously presented as a poster presentation at the American College of Physicians Northern California Chapter meeting on November 2, 2013; as an oral presentation at the Society of General Internal Medicine, California-Hawaii 2014 Regional meeting, on January 31, 2014; and as a poster presentation at the Society of Hospital Medicine Annual Meeting on March 25, 2014.

Conflicts of Interest: The authors each declare that they have no conflicts of interest.

Corresponding Author: Molly A. Kantor, MD; Stanford University School of Medicine, 300 Pasteur Drive, Lane 154, Stanford, CA 94305, USA (e-mail: mkantor2@stanford.edu).

\section{REFERENCES}

1. Wahls TL, Cram PM. The frequency of missed test results and associated treatment delays in a highly computerized health system. BMC Fam Pract. 2007;8(1):32.

2. Moore C, McGinn T, Halm H. Tying up loose ends: Discharging patients with unresolved medical issues. Arch Intern Med. 2007;167(12):1305-11.

3. Hesselink G, Schoonhoven L, Barach P, et al. Improving patient handovers from hospital to primary care: A systematic review. Ann Intern Med. 2012;157(6):417-28.

4. Forster AJ, Murff HJ, Peterson JF, Gandhi TK, Bates DW. The incidence and severity of adverse events affecting patients after discharge from the hospital. Ann Intern Med. 2003;138(3):161-7.

5. Kripalani S, Lefevre F, Phillips CO, Williams MV, Basaviah P, Baker DW. Deficits in communication and information transfer between hospitalbased and primary care physicians: Implications for patient safety and continuity of care. JAMA. 2007;297(8):831-41. 
6. Gilbert AV, Patel B, Morrow M, Williams D, Roberts MS, Gilbert AL. Providing community-based health practitioners with timely and accurate discharge medicines information. BMC Health Serv Res. 2012;12(1):453.

7. Moore C, Wisnivesky J, Williams S, McGinn T. Medical errors related to discontinuity of care from an inpatient to an outpatient setting. J Gen Intern Med. 2003;18(8):646-51.

8. Greenwald JL, Denham CR, Jack BW. The hospital discharge: A review of a high risk care transition with highlights of a reengineered discharge process. J Patient Saf. 2007;3(2):97-106.

9. Schnipper JL, Kirwin JL, Cotugno MC, et al. Role of pharmacist counseling in preventing adverse drug events after hospitalization. Arch Intern Med. 2006;166(5):565-71.

10. Beers MH, Sliwkowski J, Brooks J. Compliance with medication orders among the elderly after hospital discharge. Hosp Formul. 1992;27(7):7204

11. Groene RO, Orrego C, Sunol R, Barach P, Groene O. "It's like two worlds apart": An analysis of vulnerable patient handover practices at discharge from hospital. BMJ Qual Saf. 2012;21(Suppl. 1):i67-75.

12. Bray-Hall ST. Transitional care: Focusing on patient-centered outcomes and simplicity. Ann Intern Med. 2012;157(6):448-9.

13. Goldman L, Pantilat SZ, Whitcomb WF. Passing the clinical baton: 6 principles to guide the hospitalist. Am J Med. 2001;111(9 Suppl. 2):36S9S

14. Coleman EA. Falling through the cracks: Challenges and opportunities for improving transitional care for persons with continuous complex care needs. J Am Geriatr Soc. 2003;51(4):549-55.

15. Kim CS, Flanders SA. In the clinic: Transitions of care. Ann Intern Med. 2013;158(5 Pt 1):ITC3-1-ITC-16.

16. Walz SE, Smith M, Cox E, Sattin J, Kind AJH. Pending laboratory tests and the hospital discharge summary in patients discharged to sub-acute care. J Gen Intern Med. 2010;26(4):393-8.

17. Were MC, Li X, Kesterson J, et al. Adequacy of hospital discharge summaries in documenting tests with pending results and outpatient follow-up providers. J Gen Intern Med. 2009;24(9):1002-6.

18. Cadwallader J, Asirwa C, Li X, Kesterson J, Tierney WM, Were MC. Using computerized provider order entry to enforce documentation of tests with pending results at hospital discharge. Appl Clin Inform. 2012;3(2): 154-63.

19. Roy CL, Poon EG, Karson AS, et al. Patient safety concerns arising from test results that return after hospital discharge. Ann Intern Med. $2005 ; 143(2): 121-8$
20. Rennke S, Nguyen OK, Shoeb MH, Magan Y, Wachter RM, Ranji SR. Hospital-initiated transitional care interventions as a patient safety strategy: A systematic review. Ann Intern Med. 2013;158(5 Pt 2):433-40.

21. Horwitz LI, Krumholz HM, Green ML, Huot SJ. Transfers of patient care between house staff on internal medicine wards. Arch Intern Med. 2006;166(11):1173-7.

22. McMahon LF. The hospitalist movement: Time to move on. N Engl J Med. 2007;357(25):2627-9.

23. Kosecoff J, Kahn KL, Rogers WH, et al. Prospective payment system and impairment at discharge: The "quicker-and-sicker" story revisited. JAMA. 1990;264(15):1980-3.

24. Stanford facts: About Stanford 2014. Available at: http:// facts.stanford.edu/about/hospital. Accessed October 4, 2014.

25. Kaboli PJ, Go JT, Hockenberry J, et al. Associations between reduced hospital length of stay and 30-day readmission rate and mortality: 14-year experience in 129 Veterans Affairs hospitals. Ann Intern Med. 2012;157(12):837-45.

26. Alpers A. Key legal principles for hospitalists. Am J Med. 2001;111(9 Suppl. 2):5S-9S

27. Poon EG, Gandhi TK, Sequist TD, Murff HJ, Karson AS, Bates DW. I wish I had seen this test result earlier!". Arch Intern Med. 2004; 164(20):2223-8.

28. Marcus AC, Crane LA, Kaplan CP, et al. Improving adherence to screening follow-up among women with abnormal Pap smears: Results from a large clinic-based trial of three intervention strategies. Med Care. 1992;30(3):216-30.

29. Poon EG, Haas JS, Puopolo AL, et al. Communication factors in the follow-up of abnormal mammograms. J Gen Intern Med. 2004;19(4):31623.

30. Boohaker EA, Ward RE, Uman JE, McCarthy BD. Patient notification and follow-up of abnormal test results: A physician survey. Arch Intern Med. 1996;156(3):327-31

31. Dalal AK, Poon EG, Karson AS, Gandhi TK, Roy CL. Lessons learned from implementation of a computerized application for pending tests at hospital discharge. J Hosp Med. 2011;6(1):16-21.

32. Dalal AK, Schnipper JL, Poon EG, et al. Design and implementation of an automated email notification system for results of tests pending at discharge. J Am Med Inform Assoc. 2012;19(4):523-8.

33. Stanford Hospital and Clinics. Test directory. Available at: http:// www.stanfordlab.com/LabTestGuide/search.aspx. Accessed October 4, 2014 